\title{
IDENTIFYING EPITOPES OF HIV-1 THAT INDUCE PROTECTIVE ANTIBODIES
}

\section{Susan Zolla-Pazner}

During the past 20 years, the pendulum of opinion in the HIV-1 vaccine field has swung between two extremes, initially favouring the induction of antibodies only, and subsequently favouring the induction of cell-mediated immune responses only. At present, the consensus seems to be that induction of both humoral and cellular immunity by an HIV-1 vaccine will be required to achieve maximum protection. One obstacle to the development of an effective HIV-1 vaccine has been the difficulty in inducing broadly reactive, potent antibodies with protective functions. Defining epitopes and designing immunogens that will induce these antibodies is one of the main challenges that now confronts the HIV-1 vaccine field.
ACTIVE IMMUNIZATION The induction of immunity with immunogens that activate and expand the endogenous immune repertoire, eliciting antibodies and cell-mediated immunity, as well as immunological memory that might last for decades.

PASSIVE IMMUNIZATION Immunity that is provided rapidly by the transfer of immunoglobulins, the maximal activity of which lasts for $\sim 2-3$ weeks before it wanes due to catabolic destruction.
New York Veterans Affairs Medical Center and NYU School of Medicine, New York 10016, USA. e-mail:zollas01@endeavor. med.nyu.edu doi:10.1038/nri1307
Although cell-mediated immunity is crucial for controlling and eradicating infection by many viruses, antibodies are pivotal in preventing or modulating infection ${ }^{1,2}$. Even during early phases of infection, when the level of antibodies induced by ACTIVE IMMUNIZATION or administered by PASSIVE IMMUNIZATION is low, antibodies can reduce the size of the infecting inoculum and neutralize or eliminate virions during the first rounds of replication. This provides sufficient transient protection so that the cellular arm of the immune response can respond with proliferation and deployment of effector $\mathrm{T}$ cells that are required to eliminate virus-infected cells. Data indicate that this model is applicable to infection with HIV-1, simian immunodeficiency virus (SIV) and the chimeric simian/human immunodeficiency virus (SHIV) $)^{3-5}$.

Despite extensive data supporting the general importance of antibodies in preventing virus infections (FIG. 1), perceptions about the role of antibodies in preventing infection with HIV-1 have varied markedly over the past 20 years. Opinions have ranged from the wildly optimistic views held in the late 1980s that antibodies would be sufficient to protect against infection, to the bleakest predictions of the mid-1990s that primary isolates were resistant to antibodymediated neutralization and that no vaccine would ever be able to induce antibodies that are sufficiently broad and potent to provide protection. Many passive immunization experiments in various experimental models have, however, repeatedly established that antibodies can provide sterilizing immunity against HIV-1 (REFS 6-9). In addition, passive immunization experiments indicate that antibodies reduce the size of the infectious inoculum and allow the development of more effective cellular and humoral immune responses to the breakthrough virus ${ }^{3}$. These studies provide convincing data in all of the experimental models tested that neutralizing antibodies with appropriate specificity - when present in sufficient concentrations - are a correlate of immune protection. Even in humans, some studies indicate that antibodies transferred across the placenta might protect against transmission of HIV-1 from infected pregnant women to their infants ${ }^{10,11}$, although more studies of this controversial issue in humans are required.

\section{Protective mechanisms of antibodies}

Antibodies can protect against virus infection by many mechanisms (FIG. 1). The main mode of protection that is induced by most antiviral vaccines seems to be mediated by neutralizing antibodies ${ }^{1}$. Neutralization 


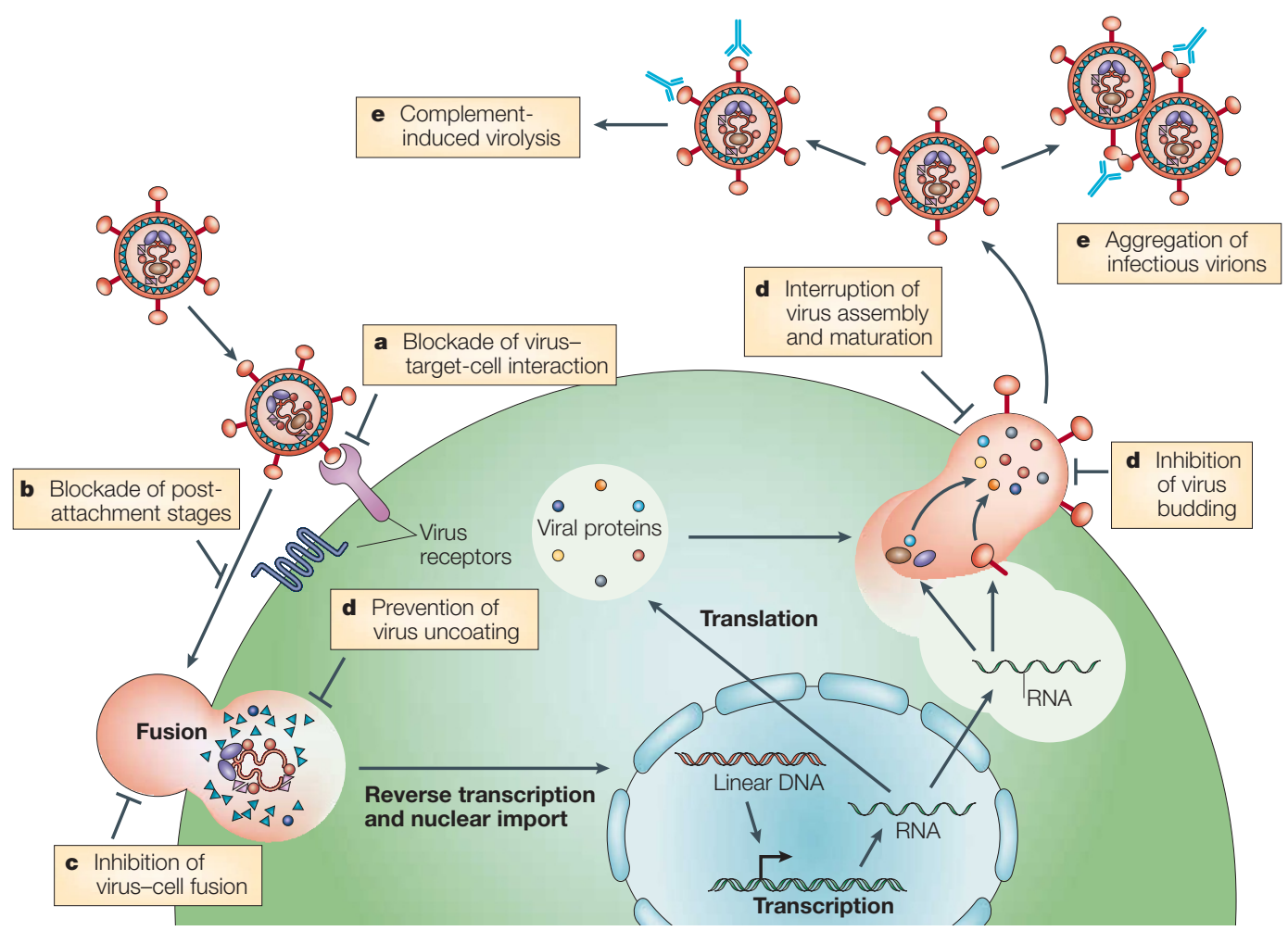

Figure 1 | Steps at which antibodies can potentially interfere with virus replication, using HIV-1 as an example.

a Antibodies can block the virus-target-cell interaction by several mechanisms, such as by: inhibiting the interaction of cell-derived molecules (such as adhesion molecules and lectins) carried in the virus envelope with their ligands on the surface of target cells; inhibiting the binding of virions to CD4 and co-receptors on the cell surface; and preventing conformational changes of the virus envelope that are required for subsequent steps in the virus life cycle. $\mathbf{b} \mid$ After attachment of the virus to target cells, antibodies can inhibit further conformational changes in the virus envelope glycoproteins that create or expose domains involved in virus-target-cell fusion. $\mathbf{c} \mid$ Antibodies can also block the protein domains that are involved in virus-cell fusion. $\mathbf{d} \mid$ At later stages in the virus life cycle, antibodies might be involved in: preventing virus uncoating after entry; interrupting virus assembly; preventing maturation of the virus particle; and inhibiting virus budding. e $\mid$ Additional mechanisms of antibody-mediated neutralization include complement-induced virolysis and aggregation of infectious virions.

is a generic term for the ability of antibodies to reduce the infectivity of a virus particle by interfering at one of several different steps in the virus life cycle. For example, antibodies can bind to molecules on the surface of virions and prevent their interaction with cellsurface lectins and with various receptors ${ }^{12,13}$. In the case of HIV-1, this type of inhibition is attributed to carbohydrate-specific antibodies that target the virus glycoproteins ${ }^{14,15}$, to antibodies that target different adhesion molecules ${ }^{16}$, and to antibodies that are specific for various regions of gp120 such as the CD4-binding domain, the 'CD4-induced (CD4i) epitope' (located in the bridging sheet of gp120 that is created or exposed when gp120 interacts with $\mathrm{CD} 4)^{17}$, and the V2 and V3 loops (see FIG. 2 and BOX 1). In addition, many 'post-attachment' mechanisms have been documented. An example of this is provided by antibodies that prevent the fusion of virus and cell membranes. In the case of HIV-1, the human monoclonal antibody 2F5 (described later) might be such an antibody, preventing either the formation of the gp41 coiledcoil form or the fusion of virus and the cell membrane ${ }^{18-21}$. Antibodies can also mediate postfusion neutralization of many viruses (although this has not yet been shown for HIV-1), blocking late stages in the virus life cycle ${ }^{12}$. Therefore, antibodies can prevent the primary uncoating of the virus in the cytoplasm, transcription steps in the nucleus, and virus assembly and budding at the cell membrane as the virus exits the cell.

Additional mechanisms by which antibodies can mediate protection include aggregation of virus particles, which reduces the size of the inoculum and renders virions more susceptible to phagocytosis and destruction ${ }^{12}$, and lysis of enveloped viruses by binding to the virion and initiating the complement cascade ${ }^{22}$. Antibodies might also attack virus-infected cells; for example, antibody-dependent cell-mediated cytotoxicity (ADCC) is a well-documented antiviral mechanism that controls virus infection, which has been shown to affect HIV-1-infected cells $s^{23,24}$.

\section{Identification of protective epitopes}

Given the 'rediscovered' importance of antibodies in the prevention of HIV-1 infection ${ }^{25}$, it is necessary to reexamine the question of which antibodies should be induced and how this might be achieved. As the most consistent correlate of immune protection against viral 
infections is the presence of neutralizing antibodies ${ }^{1,12}$, emphasis has been placed on identifying antibodies that neutralize HIV-1.

As with most pathogens, HIV-1 induces a polyclonal antibody response to a wide array of epitopes on different viral proteins ${ }^{26,27}$. Studies of polyclonal sera have helped to identify the specificities of antibodies that are associated with protection ${ }^{28,29}$, but it is the study of human monoclonal antibodies that has most clearly defined the few epitopes that are located in the two envelope glycoproteins, gp120 and gp41, that induce neutralizing antibodies in natural infection (TABLE 1) and mediate protection against infection in passive immunization studies. Induction of antibodies to each of these epitopes might ultimately be useful as a defensive shield against HIV-1 infection; however, each of these epitopes presents challenges to vaccine design.
Constant regions of the virus envelope as targets Antibodies to epitopes in gp41. Several human monoclonal antibodies specific for gp41 have been produced, and several epitopes within gp4 1 have been defined ${ }^{27,30,31}$ (FIG. 3, TABLE 1 and BOX 1). However, only a small minority of gp41-specific antibodies have neutralizing activity. One human monoclonal antibody, 2F5, has been shown to have broad neutralizing activity for diverse primary HIV-1 isolates ${ }^{32}$. This monoclonal antibody recognizes a core epitope of six amino acids within a relatively conserved 16-amino-acid linear sequence (NEQELLELDKWASLWN) in the ectodomain of gp41 near the transmembrane region of the molecule ${ }^{33}$. Two additional human monoclonal antibodies, $4 \mathrm{E} 10$ and Z13, which are specific for the transmembrane proximal region of gp41 in a region immediately carboxy-terminal to the 2F5 epitope, also have broad neutralizing activity ${ }^{34}$. Epitopes in this region of gp41 are poorly exposed on

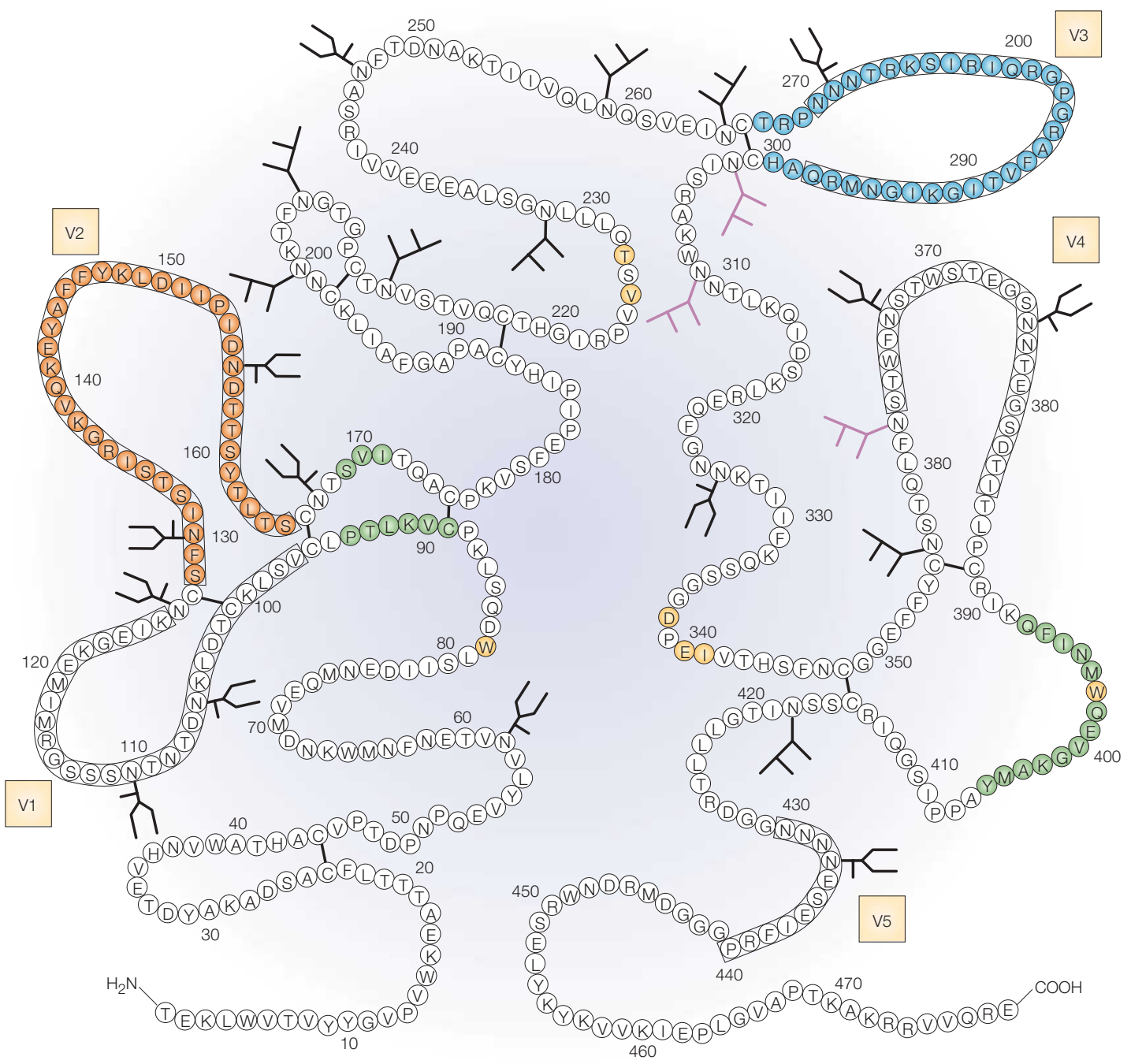

Figure 2 | Diagram of the structure of the HIV-1 envelope glycoprotein gp120. The gp120 molecule with the location of the variable regions marked in boxes (V1-V5). The glycosylation sites containing high mannose-type and/or hybrid-type oligosaccharide structures are indicated by the branched structures, and glycosylation sites containing complex-type oligosaccharide structures are indicated by the U-shaped branches. Epitopes in gp120 that induce neutralizing antibodies are highlighted in colour. These include the highly conformational CD4-binding domain (key epitopes highlighted in yellow), the CD4-induced epitope (green), an epitope composed of $\alpha 1 \rightarrow 2$ mannose residues (purple), the V2 loop (orange) and the V3 loop (blue). Reproduced with permission from REF. 63 () (1990) American Society for Biochemistry and Molecular Biology. 
both the surface of intact virus particles and the membranes of virus-infected cells $\mathrm{s}^{35-37}$. Studies showing that exposure of these epitopes is altered by CD4induced changes in the envelope $\mathrm{e}^{35}$ and that monoclonal antibodies such as 2F5 bind poorly to virions yet can neutralize the virus ${ }^{37}$ indicate that these monoclonal antibodies recognize epitopes that have accessibility changes during the course of infection ${ }^{35,37}$. Such antigenic determinants, the exposure of which occurs during limited periods during virus infectivity, are characterized as 'transitional epitopes', a term that also applies to other envelope epitopes (see later).

\section{Box $1 \mid$ Regions of HIV-1 gp41 and gp120 that are crucial to virus function and immune protection \\ gp41}

This transmembrane glycoprotein is found as a homotrimeric complex in the envelope of the virus; it interacts noncovalently with gp120 on the exterior of the virus particle.

- Immunodominant region (includes gp41 epitope cluster I): induces high levels of antibodies, most of which are not neutralizing but might mediate other functions, such as antibody-dependent cell-mediated cytotoxicity (ADCC) and aggregation of and complement deposition on virus particles.

- Transmembrane-proximal region: poorly exposed on the surface of the virus and is thought to be a transitional epitope, exposed for a brief period of time during the conformational changes that occur in gp41 that lead to the fusion of virus and cell membranes.

- Amino-terminal and carboxy-terminal heptad repeat regions: the repeating motifs in these regions form leucine zippers, which are involved in the formation of the coiled-coil form of gp41 after conformational changes are induced in gp120 by its interaction with CD4 and chemokine receptors.

- Fusion peptide: the amino-terminal region of gp41, which is exposed after formation of the coiled-coil form. This region is inserted into the membrane of the target cell, resulting in the fusion of virus and cell membranes.

gp120

Three molecules of gp120 are non-covalently linked to trimeric gp41, forming hetero-oligomeric spikes on the surface of the virus particle. Different regions of gp120 interact with CD4 and chemokine receptors found on the surface of target cells. These interactions lead to a series of conformational changes in gp120, and subsequently allow the conformational changes in gp41 that lead to formation of the coiled-coil form and exposure of the fusion peptide. - CD4-binding domain (CD4bd): composed of several parts of the gp120 molecule, forming a binding pocket into which a region of $\mathrm{CD} 4$ fits.

- Bridging sheet: composed of four anti-parallel $\beta$-strands from the V1/V2 stem and the C4 regions of gp120. This region is involved in the binding of gp120 to chemokine receptors, triggering subsequent conformational changes in gp120 and gp41. Because this region forms or is exposed after binding of gp120 to CD4, it is known as the 'CD4induced epitope'.

- V2 loop: a highly variable region that is proximal to the CD4bd and is part of the bridging sheet. The V2 loop (together with the V1 loop) seems to shield partially the CD4bd, the bridging sheet and part of the V3 loop until conformational changes in gp120 are induced by CD4.

-V3 loop: a semi-conserved region of gp120 that is structurally constrained by its requisite participation in virus infectivity. The V3 loop interacts with chemokine receptors on the surface of target cells.

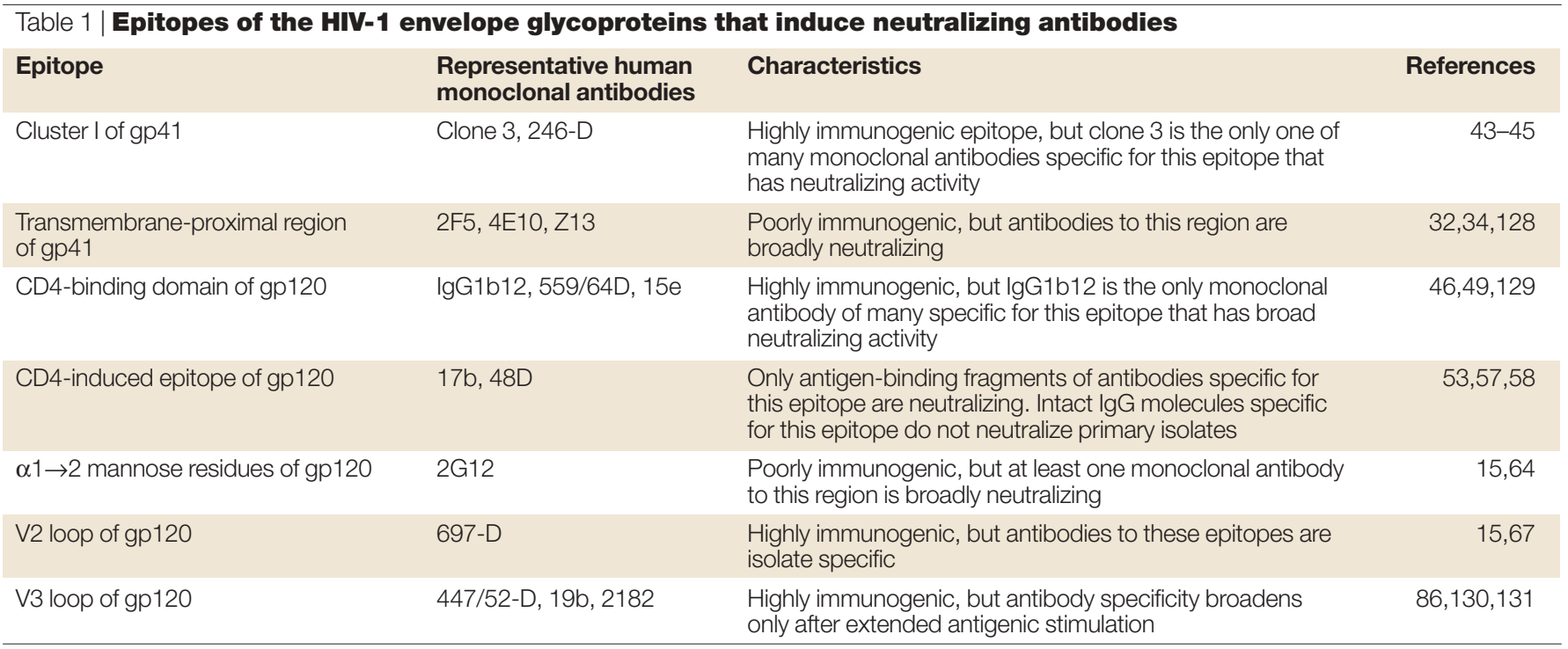


IMMUNODOMINANT

The antigenic determinant(s)

within a complex mixture (such as a protein or whole virus) that preferentially stimulates a strong immune response.

T-CELL-LINE-ADAPTED VIRUS HIV strains that are adapted for growth in tissue culture on transformed $\mathrm{T}$ cells.
Data indicate that antibodies to the membraneproximal region of gp 41 might prevent infection by blocking either the formation of the gp 41 coiled-coil form or gp41-mediated changes that lead to the fusion of virus and cell membranes ${ }^{18-21,38}$. However, this region of gp41 - especially the core epitope that is recognized by monoclonal antibody 2F5 (ELDKWA) - seems to be poorly immunogenic, as antibodies specific for this epitope occur infrequently in HIV-1-infected individual $s^{39,40}$. Moreover, experimental immunogens that consisted of the 2F5 epitope inserted into either the influenza virus haemagglutinin antigen, the hepatitis B virus surface antigen or the Escherichia coli MaIE protein failed to elicit antisera with neutralizing activity for primary isolates ${ }^{40-42}$. Therefore, this interesting epitope seems to require a particular molecular context, but this context might reduce the efficiency of its presentation to the immune system.

A human monoclonal antibody, clone 3 , to an epitope that spans the disulphide bond in the IMMUNODOMINANT loop of the ectodomain of gp41 (GCSGKLICTT) has also been shown to neutralize primary isolates ${ }^{43,44}$. Interestingly, human monoclonal antibodies (such as monoclonal antibody 246) that recognize epitopes that are offset by 5-7 amino acids upstream of the clone 3 epitope do not have this neutralizing capacity ${ }^{30,45}$.

Antibodies to the CD4-binding domain of gp120. The CD4-binding domain (CD4bd) in the gp120 molecule (FIG. 2 and BOX 1) is a highly conserved, complex, conformation-dependent region which, by definition, is responsible for the interaction between the virus envelope and the CD4 molecule on the surface of target cells. Because this interaction is pivotal to the process by which HIV-1 infects, it was assumed that antibodies specific for the CD4bd would be particularly effective at blocking infection, and, indeed, many monoclonal antibodies to this region do neutralize T-CELL-LINE-ADAPTED VIRUSES $^{46,47}$. However, most CD4bd-specific monoclonal antibodies (exemplified by monoclonal antibodies $559 / 64 \mathrm{D}$ and $15 \mathrm{e}$ ) do not neutralize primary isolates for reasons that are still not well understood ${ }^{45,48}$. An exception is the human monoclonal antibody IgG1b12, which was constructed using recombinant technology from the bone marrow of an HIV-1-infected donor ${ }^{49}$. This monoclonal antibody has exceptionally broad activity against primary isolates, thereby confirming the crucial role of the CD4bd in HIV-1 infection ${ }^{32,50}$. Given the complexity of the CD4bd and the paucity of CD4bd-specific monoclonal antibodies with neutralizing activity, the design of an immunogen that will give rise to neutralizing antibodies specific for this epitope will be a challenge.

An additional observation complicates the rationale for eliciting CD4bd-specific antibodies. Antibodies to the CD4bd have recently been shown to interfere with the processing of gp120 by antigen-presenting cells and to block the subsequent presentation of gp 120 epitopes to envelope-specific T helper cells ${ }^{51,52}$. These findings indicate that the induction of antibodies that are specific for the CD4bd, even CD4bd-specific

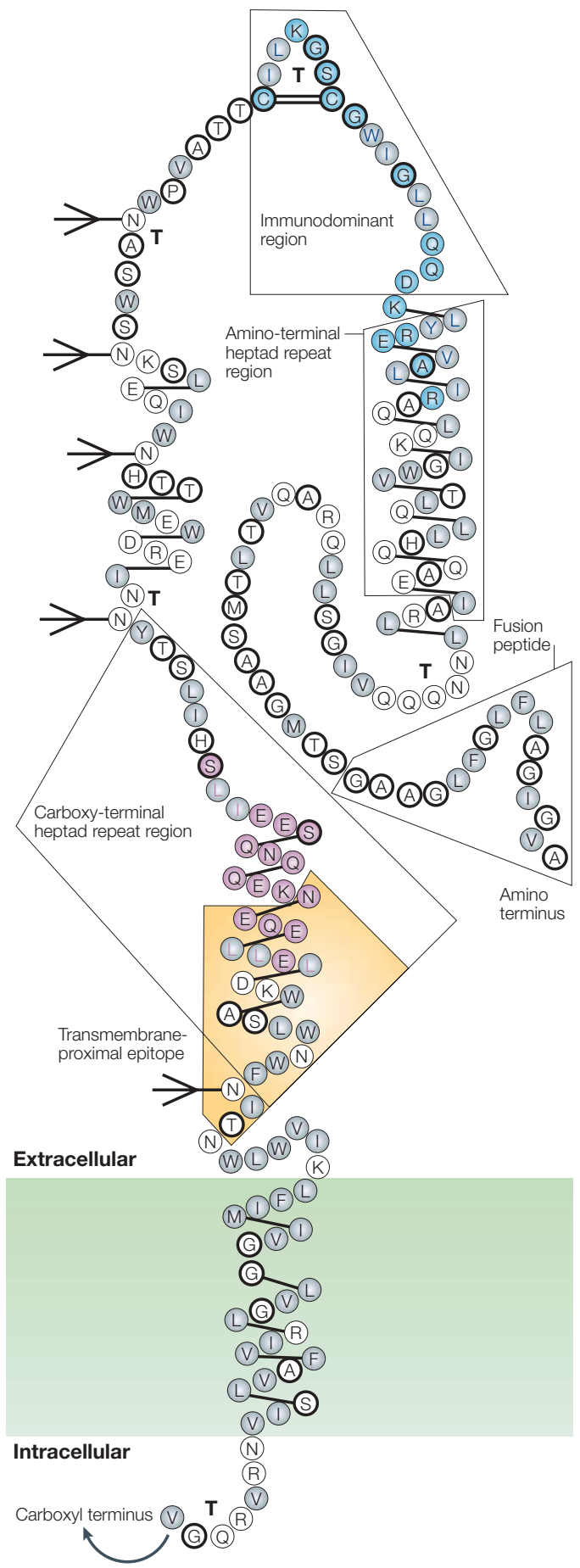

Figure 3 | Diagram of the structure of the HIV-1 envelope glycoprotein gp41. The gp41 molecule with $\alpha$-helices depicted as alternating three- and four-amino-acid groupings connected by single lines, hydrophobic amino acids indicated as grey circles, charged amino acids as unfilled circles and neutral amino acids as heavily outlined circles. Strong turns are indicated by ' $T$ ', and potential glycosylation sites by branched-stick figures. Key functional and structural regions are boxed, and well-characterized epitopes are shown in colour, with epitope clusters I and II shown in turquoise and pink, respectively, and the transmembrane-proximal epitope highlighted in yellow. Reproduced with permission from REF. 126 (c) (1989) Mary Ann Liebert Inc. Publishers. 
monoclonal antibodies with neutralizing activity, could potentially inhibit the development of effective cellular immune responses to the virus envelope. Of note, antibodies specific for other epitopes of gp120 do not have this effect ${ }^{51}$.

Antibodies to the CD4-induced epitope of gp120. Antibodies are found in HIV-1-infected individuals that react better with gp 120 when it is complexed with soluble CD4; the conformational changes in gp120 that are induced by soluble CD4 create or expose the CD4i epitope $^{53}$. The region recognized by CD4i-specific monoclonal antibodies has now been mapped to regions of gp120 that are involved in its binding to chemokine receptors ${ }^{54-56}$, recognizing epitopes formed by $\beta$-strands in the V1/V2 stem and the $\mathrm{C} 4$ region $^{57}$. Several such human monoclonal antibodies have been identified $^{53,57,58}$, showing that the relevant epitope(s) are immunogenic at least in a subset of infected individuals. One monoclonal antibody specific for the CD4i epitope, monoclonal antibody $17 \mathrm{~b}$, has been particularly useful in crystallographic studies of gp120 (REF. 59), but, surprisingly, monoclonal antibody $17 \mathrm{~b}$ and other monoclonal antibodies to this epitope (such as 48D) in their complete IgG form do not neutralize most of the primary isolates tested ${ }^{57}$. Interestingly, the antigenbinding fragment $(\mathrm{Fab})$ and single-chain fragments of these CD4i-specific monoclonal antibodies do have neutralizing function ${ }^{58,60}$. The inability of the whole $\operatorname{IgG}$ CD4i-specific monoclonal antibody to neutralize can be explained by steric hindrance, given that the distance between the CD4i epitope on gp120 and the target cell membrane in molecular models seems too small to accommodate the entire IgG molecule ${ }^{61,62,132}$. If these observations are confirmed, the physical constraints on antibody access to the CD4i epitope will preclude the use of antibodies to this epitope as a barrier against infection with HIV-1.

Antibodies to carbohydrate epitopes of gp120. Given that $\sim 50 \%$ of the mass of gp120 is composed of carbohydrate moieties ${ }^{63}$, it is perhaps not surprising that antibodies to carbohydrates have neutralizing activity against HIV-1 (REF. 14). The best studied of the neutralizing carbohydrate-specific antibodies of human origin is the monoclonal antibody $2 \mathrm{G} 12$, which targets a cluster of carbohydrate moieties in gp120 (FIG. 2); this monoclonal antibody has broad neutralizing activity for both T-cell-line-adapted and primary isolates of HIV-1 (REFS 15,64). Crystallographic studies have revealed its unusual structure, which allows for multivalent interaction with a conserved cluster of oligomannose-type sugars ${ }^{65}$; however, the extremely unusual configuration of this monoclonal antibody and the poor immunogenicity of the epitope recognized by monoclonal antibody 2G12 (REF. 64) raise several questions. What is the probability that a vaccine could regularly elicit such antibodies? How could an immunogen be designed to mimic the unique cluster of oligomannose residues targeted by 2 G12? And, what is the mechanism by which this monoclonal antibody mediates neutralization, given the location of this epitope on a surface of gp120 that is not known to be involved in virus attachment or fusion?

Variable regions of the virus envelope as targets The V2 and V3 variable loops of gp120 (FIG. 2 and BOX 1) have long been recognized to contain epitopes that induce potent neutralizing antibodies ${ }^{66-70}$. However, scepticism persists concerning the protective value of antibodies to variable regions of gp 120, because these antibodies are thought to be isolate specific, and because the variable nature of these regions is thought inevitably to allow HIV-1 to escape the effects of these antibodies $^{62,71}$.

Antibodies to the V2 region. Scepticism about the use of V2-specific antibodies might be warranted. Although studies of polyclonal antibodies specific for the $\mathrm{V} 2$ region show potent antiviral neutralizing activity ${ }^{66,67,72}$, broad neutralizing activity against primary viruses is not a general property of V2-specific antibodies, as shown by the inability of several rodent and human V2-specific monoclonal antibodies (such as monoclonal antibody 697-D) to neutralize panels of T-cell-line-adapted and primary isolates ${ }^{73}$ (M. K. Gorny, unpublished observations). This seems to be due to the fact that the $\mathrm{V} 2$ region varies not only in sequence but also in length, due to insertions and deletions that alter or eliminate conserved elements to which broadly neutralizing antibodies could be targeted. Given that viruses lacking the V1/V2 region or the V2 variable loop are capable of replication ${ }^{74,75}$, this region cannot be essential for infectivity and therefore is relatively unconstrained in terms of mutation. Therefore, despite the fact that this region of the virus envelope carries out important functions - mediating gp41-independent interaction within the gp120 trimer $^{76}$ and shielding the region in and around the bridging sheet of gp120 responsible for interaction with chemokine receptors ${ }^{74,75,77-79}$ - the V1/V2 loop is an improbable target for vaccines and, in fact, is specifically being deleted in some vaccine constructs to provide better access to neutralizing epitopes in and near the co-receptor binding site ${ }^{80}$.

In contrast to the variable nature of the V1/V2 region, the stem of the V1/V2 loop is relatively well conserved and is involved in the formation of the chemokine-receptor-binding site and interaction with CD4 (REFS 77,81). This indicates that the V1/V2 stem has a crucial role, which makes it a potentially valuable target of antibodies. However, no antibodies specific for this region have yet been described, indicating that this site is poorly immunogenic and/or is poorly or only transiently exposed.

Antibodies to the V3 loop. Similar to the V2 loop, the amino-acid sequence of the V3 loop is variable, but V3 is distinct from V2 in both its structural characteristics and function. Due to the variable nature of V3, some V3-specific antibodies, similar to V2-specific antibodies, are isolate specific. Such isolate-specific V3-specific 
antibodies are mainly produced early after infection or after brief immunization protocols ${ }^{68,69,82,83}$. Moreover, most V3-specific monoclonal antibodies produced by infected individuals and selected using linear V3 peptides have little neutralizing activity for primary isolates despite broad immunochemical crossreactivity ${ }^{45,84,85}$. However, in addition to isolate-specific V3-specific antibodies, broadly reactive $\mathrm{V} 3$-specific antibodies with potent neutralizing activity have been described; such polyclonal and monoclonal V3-specific antibodies are conformation sensitive rather than specific for linear epitopes in the V3 loop ${ }^{86}$. The most broadly reactive of the neutralizing V3-specific monoclonal antibodies can neutralize a large proportion of clade B HIV-1 primary isolates ${ }^{87-90}$, and have also been shown to neutralize viruses from clades $\mathrm{A}$ and $\mathrm{F}$, which, by definition, must have shared or crossreactive epitopes ${ }^{86}$.V3-specific antibodies with broad specificity and functional activity (similar to monoclonal antibodies 447/52-D, $19 \mathrm{~b}$ and 2182) are probably produced later in infection as a result of SOMATIC HYPERMUTATION in the variable-region immunoglobulin genes that occurs during maturation of the humoral immune response to any given antigen ${ }^{91}$. This apparent requirement for prolonged antigenic stimulation to induce broadly reactive V3specific antibodies is a challenging problem in terms of designing a practical vaccine strategy that will induce broadly reactive, protective V3-specific antibodies. So far, no clinical vaccine trial has addressed whether longer immunization regimens induce more broadly reactive neutralizing antibodies, in general, and more highly crossreactive V3-specific antibodies, in particular.

The surprising crossreactivity of V3-specific antibodies can be explained on the basis of both structural and functional characteristics of the V3 loop. Therefore, despite its designation as the third variable domain of gp120, and unlike the V2 region, the V3 loop is actually a semi-conserved region with many constant features, including a fixed size (30-35 amino acids), a conserved type II turn at its tip, a disulphide bond at its base and a net positive charge $\mathrm{e}^{92}$. This structural constraint is imposed by the functional requirement for the V3 loop to interact with chemokine receptors for virus infectivity ${ }^{93,94}$. Indeed, deletion of the V3 loop results in non-infectious virions ${ }^{74}$.

The conserved nature of the V3 loop is further explained by its homology to structures of the natural ligands of the virus co-receptors. This was revealed by nuclear magnetic resonance (NMR) spectroscopy of V3 peptides complexed with fragments of two V3-specific monoclonal antibodies that preferentially neutralize CC-chemokine receptor 5 (CCR5)-tropic or CXCchemokine receptor 4 (CXCR4)-tropic viruses (R5 and $\mathrm{X} 4$ viruses, respectively). These structural studies showed alternative V3 conformations that are homologous to the $\beta$-hairpin structures in the CC-chemokines CCL3 (macrophage inflammatory protein $1 \alpha, \mathrm{MIP} 1 \alpha$ ), CCL4 (MIP1 $\beta$ ) and CCL5 (RANTES), and in the CXCchemokine CXCL12 (stromal-cell-derived factor 1, SDF1), respectively ${ }^{95}$ (FIG. 4). Functional homology between the V3 loop of an X4 virus and CXCL12 was
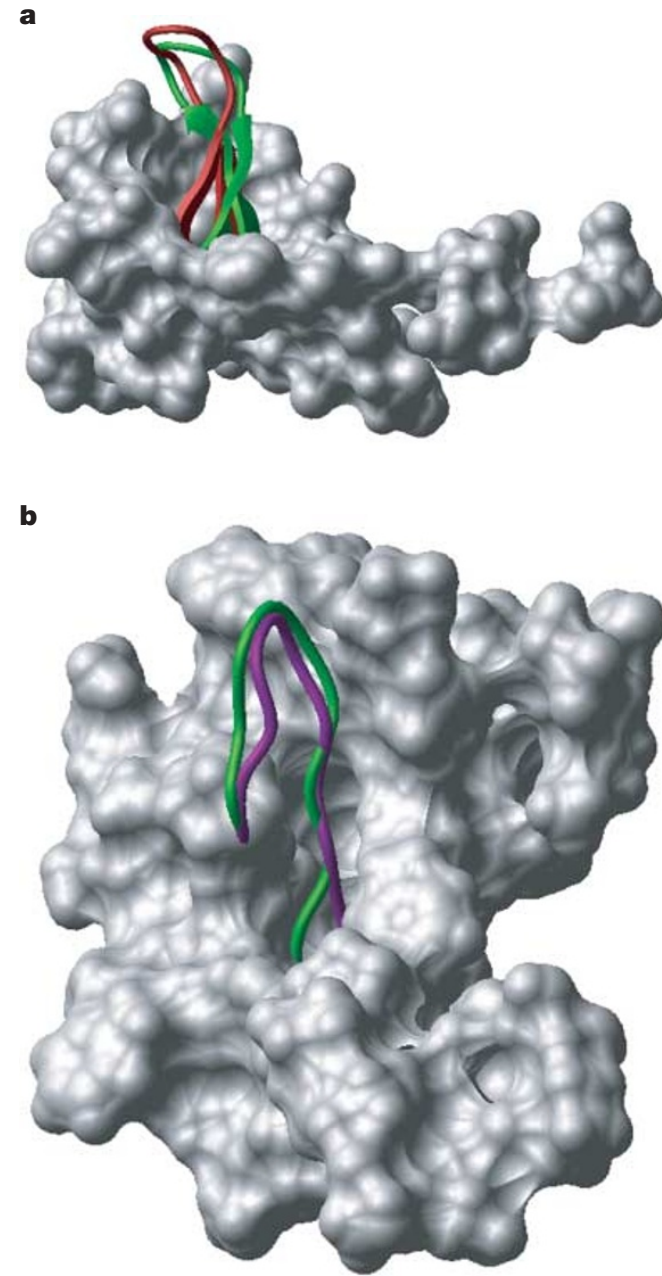

Figure 4 | Alternative conformations of HIV-1 V3 loops mimic $\beta$-hairpin structures of chemokines. a $\mid$ A spacefilled diagram of CXC-chemokine ligand 12 (CXCL12, also known as stromal-cell-derived factor 1, SDF1) with the $\beta$-hairpin structure shown as a ribbon diagram. The structure of the V3 loop of gp120 (as defined by nuclear magnetic resonance (NMR) analysis when complexed with mouse V3-specific monoclonal antibody $0.5 \beta^{95}$ ) is shown in red, superimposed on the $\beta$-hairpin of CXCL12, shown in green. b | A space-filled diagram of CC-chemokine ligand 5 (CCL5, also known as RANTES) with the $\beta$-hairpin structure shown as a ribbon diagram. The structure of the $\mathrm{V} 3 \mathrm{loop}$ (as defined by NMR analysis when complexed with human V3-specific monoclonal antibody $447 / 52-D^{95}$ ) is shown in purple, superimposed on the $\beta$-hairpin of CCL5, shown in green. Images courtesy of M. Schapira.

established by Yonezawa et al. ${ }^{96}$ who showed that infectivity was retained when the V3 loop of an X4 virus was replaced by 43 amino acids from CXCL12 a region that includes the $\beta$-hairpin domain that is structurally homologous to the V3 loop of X4 viruses. These data reveal mechanisms by which the virus envelope interacts with the chemokine receptors, support the crucial role of the $\mathrm{V} 3$ region in virus infectivity, explain why there must be marked conservation in the V3 loop, and provide a rationale for how antibodies to conserved V3 motifs can be so highly crossreactive. 
a

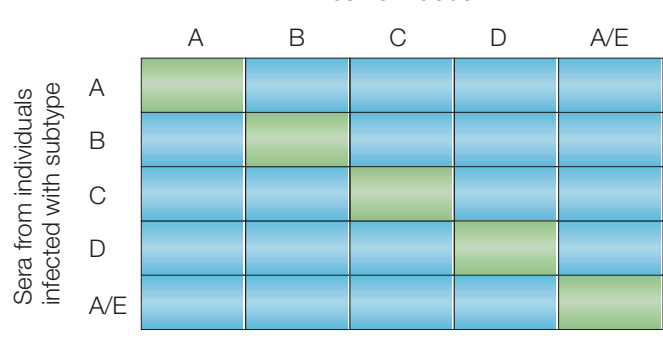

b

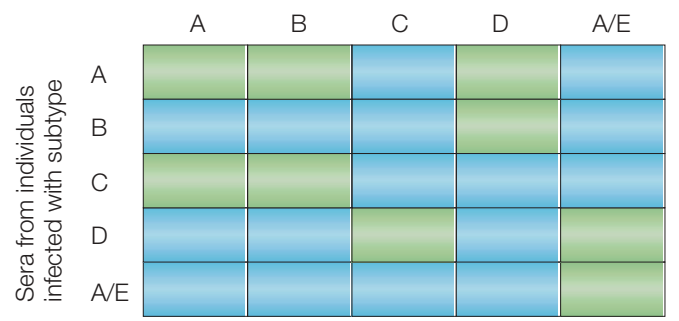

Figure 5 | Hypothetical neutralization matrices. Positive neutralization by a serum-virus pair is denoted by a green box, and the absence of neutralization is denoted by a blue box. If antibodies preferentially neutralized the virus subtype infecting the patient, then neutralization by sera from subjects infected with subtypes A, B, C, D or A/E would preferentially neutralize viruses from the same subtype, as shown in part $\mathbf{a}$. In fact, patterns approximating part $\mathbf{b}$ have been achieved in several studies $^{118-120}$, indicating that there is little correlation between the neutralizing activity of a patient's serum and the genotype of the virus infecting that patient.

These studies also prompt a re-examination of the data that underlie the long-standing dogma that V3specific antibodies are isolate specific and cannot neutralize primary isolates. For example, we now know that whereas isolate-specific V3-specific antibodies are produced early after infection or immunization ${ }^{68,69,82}$, broadly reactive $\mathrm{V} 3$-specific antibodies are characteristic of a more mature immune response ${ }^{86,88}$. Similarly, the conclusion that $\mathrm{V} 3$-specific antibodies are ineffective for neutralizing primary isolates was based on inefficient depletion of antibodies from $\mathrm{HIV}-1^{+}$sera with linear V3 peptides - a process that would have failed to effectively remove antibodies that are specific for conformation-sensitive V3 epitopes ${ }^{97,98}$. Moreover, careful review of early studies, as well as more recent data published by several groups, shows that epitopes in the V 3 loop are not cryptic but are at least partially displayed on the surface of R5 virus particles and R5virus-infected cells ${ }^{36,37,89,90,99,100}$, and that V3-specific monoclonal antibodies can neutralize R5 as well as $\mathrm{X} 4$ viruses ${ }^{86,87,89,90,101}$.

In summary, studies show that there are conserved conformations in the V3 loop that are crucial to its function, that the pattern of charged residues below the tip of the loop is important for co-receptor binding ${ }^{102}$ and that regions in the V3 loop (and chemokines) crucial to their interaction with chemokine receptors are discontinuous ${ }^{102,103}$. These elements strongly support the hypothesis that the conformation and pattern of charges of this region of the virus envelope are key to ligand-receptor interactions. So, the challenge to inducing broadly neutralizing V3-specific antibodies by immunization lies in designing an antigen that presents an immunogenic and conformationally correct V3 loop, and presenting it in a formulation and dosing schedule that will allow optimal maturation of the antibody response.

The need to identify new protective epitopes

Although many human monoclonal antibodies to various epitopes of gp120 and gp41 have been identified that neutralize HIV-1 primary isolates, and the epitopes that are recognized by these monoclonal antibodies have been carefully dissected, there might be additional protective epitopes that have not yet been identified by the presently available panel of monoclonal antibodies. These epitopes might be formed by quaternary structures that result from the interaction of the monomeric envelope subunits that form trimers on the surface of intact virions. These and other (as-yet-undefined) epitopes might be immunogenic in only a subset of individuals, might be composed of structures that appear on some but not all isolates, or might predominate on less well studied virus subtypes. Finally, new epitopes might consist of transitional epitopes and/or molecular regions that are poorly represented during the various screening regimens that are used to select monoclonal antibodies. Defining additional epitopes that induce neutralizing antibodies in HIV-1-infected individuals will provide additional scaffolds on which to model candidate vaccines.

\section{Focusing the antibody response}

The gp41 and gp120 envelope glycoproteins contain a large number of B-cell epitopes ${ }^{27,30,31}$. Current vaccine protocols induce antibodies to many epitopes rather than focusing the immune response on epitopes that will induce protective antibodies. Epitopes such as those in C5 of gp120 and near the disulphide loop in the ectodomain of gp41, for example, are immunodominant but give rise to antibodies that are generally not neutralizing ${ }^{104}$. Given that several neutralizing epitopes in gp120 and gp41 have already been identified, it would be advantageous to direct the antibody response to these protective epitopes. Several approaches are being used to focus the immune response on one or a few epitopes. For example, limited envelope deglycosylation or deletion of the V2 loop seems to create immunogens that augment the level of neutralizing antibodies by improving the exposure and/or immunogenicity of neutralizing epitopes ${ }^{80,105}$. The contrary approach hyperglycosylation - is being studied to abrogate the immunogenicity of all but one or a few key envelope epitopes ${ }^{106}$. Other approaches include the use of single or multiple-chain peptides to induce antibodies to specific regions of the envelope $e^{5,107,108}$.

Several additional new approaches have recently been proposed to design vaccine immunogens. One of these, known as REVERSE IMMUNOLOGY ${ }^{109}$, identifies peptide ligands bound by MHC molecules, T-cell receptors or immunoglobulins to define peptide immunogens that 
will be recognized by the immune system. Given the number of HIV-1-specific monoclonal antibodies with neutralizing activity that have been described, it is not surprising that a similar strategy has been used to determine the B-cell epitopes that they recognize. For example, Zwick et al. ${ }^{39}$ identified a peptide mimotope of the epitope that is recognized by monoclonal antibody IgG1b12. This peptide is a homodimer, the activity of which depends on an intact disulphide bridge that joins its polypeptide chains. Disappointingly, a vaccine constructed from this synthetic peptide and conjugated to each of two different carriers failed to elicit significant gp120 crossreactive antibodies. The broadly neutralizing V3-specific human monoclonal antibody 447/52-D has also been screened with a random phage library. Most of the peptides identified and sequenced contained the GPXR-motif characteristic of the tip of the V3 loop. One of the 15-mer peptides identified as binding strongly to monoclonal antibody 447/52-D was conjugated to a carrier and used to immunize rabbits. The sera from three of four rabbits showed neutralizing activity against two of five HIV-1 variants tested $^{110}$. These results indicate that, at least for some epitopes, the use of mimotopes defined using monoclonal antibodies might lead to the design of immunogens that will induce neutralizing antibodies. Although not a simple task, designing such mimotopes should now be more feasible as the structures of several human monoclonal antibodies with broad neutralizing activity have been studied by NMR and X-ray crystallographic analyses ${ }^{15,95,111-113,133}$. Information about the epitopes that these monoclonal antibodies recognize and the key features of their combining sites should be useful in the design of immunogens that will induce similar antibodies. The potential promise of this approach is suggested by results obtained with mimotope-based vaccines under development against human T-cell leukaemia virus type $1(\mathrm{HTLV} 1)^{114}$, measles ${ }^{115}$, coronavirus ${ }^{116}$ and herpes simplex virus 2 (HSV2) ${ }^{117}$.

\section{Box 2 | Lessons for HIV-1 vaccine design}

- It might be useful to target the antibody response to neutralizing epitopes rather than to immunize with native molecules or constructs based on whole molecules bearing many neutralizing and non-neutralizing epitopes.

- Most, if not all, neutralizing epitopes are conformation sensitive, indicating that peptide immunogens might not present the optimal 'shapes' to the immune system.

- The V3 loop should be considered as a 'semi-conserved region' due to its structural and conformational conservation, and might therefore be as valuable a target for vaccines as envelope constant regions for the induction of neutralizing antibodies.

- An increased emphasis should be placed on the design of immunogens that will induce antibodies specific for the various constant and variable domains that interact with chemokine receptors.

- An increased emphasis should be placed on inducing antibodies that interfere with the required conformational changes in gp41.

- Virus diversity poses a challenge to vaccine development. This might be addressed by recognizing the need for a polyvalent $\mathrm{HIV}-1$ vaccine, by identifying representative viruses to include in such a vaccine, and by recognizing that, despite virus diversity, there are constant features on the virus envelope that are required for interaction with its receptor and co-receptors.

\section{The need for polyvalent vaccines}

Some of the epitopes discussed earlier that could serve as targets of neutralizing antibodies are found in constant regions of the virus envelope; others are localized to variable regions. Although some variable epitopes, such as the $\mathrm{V} 3$ region, retain conserved elements, present data indicate that, at the very least, more than two conformations exist. Therefore, to induce antibodies to neutralizing epitopes in variable regions, polyvalent vaccines will be required. This requirement for polyvalent vaccines against antigenically variable pathogens is well established, given the requirement for multiple-strain-based vaccines against organisms such as polio virus, influenza virus and Streptococcus pneumoniae. For these vaccines, extensive research was necessary to identify which and how many strains were required for maximum protection. In the case of influenza virus, the choice of vaccine strains is an ongoing concern as the antigenic nature of the organism is constantly changing. Similar challenges probably face the HIV-1 vaccine field.

It is highly unlikely that a single construct will protect against all subtypes of HIV-1. Given the continuing evolution of the virus and the spread of subtypes throughout the world, the question is how to choose which and how many strains need to be represented in a vaccine to give maximum protection. Initial approaches to designing polyvalent HIV-1 vaccines have been based on choosing viruses that are representative of genetically defined 'clades' (or subtypes). Clades are defined on the basis of the nucleotide sequences of the HIV-1 genome, including those genes that encode the HIV-1 envelope glycoproteins. So far, three groups of HIV-1 have been identified ( $\mathrm{M}, \mathrm{N}$ and $\mathrm{O}$ ). Within group $\mathrm{M}$, which is the main group that infects patients worldwide, nine clades and 14 circulating recombinant forms have been identified. Several studies have shown that sera from HIV-1 infected individuals might neutralize several primary isolates from various clades with similar potency ${ }^{118-120}$. So, with the exception of clades $B$ and $E$, which show distinct antigenic differences ${ }^{121}$, there seems to be no particular preference for sera from patients infected with one clade to neutralize other viruses from the same clade; a diagramatic representation of this is shown in FIG. 5. Similarly, studies of HIV-1-specific human monoclonal antibodies, most of which come from clade-B-infected individuals (such as those listed in TABLE 1) show their comparable potency in neutralizing many viruses from various clades ${ }^{32,86,122}$. These data raise important questions about the relevance of HIV-1 genotypic classification in vaccine design. Therefore, in addition to genotypic classification, other approaches are being used to identify representative viruses for inclusion in a polyvalent HIV-1 vaccine. Bioinformatic techniques are being used to search the HIV-1 sequence database for common epitopes that could induce cross-clade immunity ${ }^{123}$. Related techniques are being used to identify or construct HIV-1 envelope proteins that have antigenic similarities to presently circulating strains or to ancestral viruses that might more effectively elicit crossreactive immune responses ${ }^{124}$. A third approach is based on immunological studies of the HIV-1 
envelope glycoproteins in an attempt to classify HIV-1 strains in terms of their immunological characteristics. For this, cluster analysis of immunochemical and neutralization data with polyclonal and monoclonal antibodies is being used to determine the existence of immunologically related classes of HIV-1 ('immunotypes') or groups of viruses defined by their ability to be neutralized by sets of monoclonal antibodies ('neutrotypes' $)^{119,125}$. The value of each of these methods has yet to be established, but the clear need for a polyvalent HIV-1 vaccine and the absence of data supporting the general relevance of genotypic classification for choosing HIV-1 strains for inclusion in a vaccine indicate that these and additional approaches need to be pursued actively.

\section{Conclusions}

Experience with viral vaccines that are in use at present, and results from extensive studies of HIV-1, SIV and SHIV, strongly indicate that an effective HIV-1 vaccine will need to induce both broadly reactive neutralizing antibodies and cell-mediated immunity. Potent and broadly reactive neutralizing antibodies have been described in studies of sera from HIV-1-infected subjects and by the study of neutralizing monoclonal antibodies derived from the cells of HIV-1-infected individuals. Therefore, protective antibodies are represented in the human B-cell repertoire; however, inducing these antibodies with candidate vaccines has proven difficult because, although a broad range of antibodies are produced in most individuals or animals immunized with candidate vaccines, the antisera have limited neutralizing activity measured by either qualitative or quantitative means.

The design of new immunogens and new approaches might be informed by the epitopes that have been described that are targeted by human neutralizing antibodies. Each of these epitopes presents unique challenges to vaccine design, but useful nuances and patterns emerge (BOX 2). From these studies, it becomes clear that research over the past decade has documented the ability of the human immune system to produce protective antibodies against HIV-1. The challenge of the coming decade is to understand how to build immunogens that will stimulate B cells to make these antibodies.
1. Robbins, J. B., Schneerson, R. \& Szu, S. C. Perspective: hypothesis: serum $\lg G$ antibody is sufficient to confer protection against infectious diseases by inactivating the inoculum. J. Infect. Dis. 171, 1387-1398

(1995).

A review of the data that support the hypothesis that serum antibodies confer protection against viruses and bacteria by inactivating these pathogens.

2. Hilleman, M. R. Overview of the pathogenesis, prophylaxis and therapeusis of viral hepatitis B, with focus on reduction to practical applications. Vaccine $\mathbf{1 9}$, 1837-1848 (2001)

3. Haigwood, N. L. et al. Passive immune globulin therapy in the SIV/macaque model: early intervention can alter disease profile. Immunol. Lett. 51, 107-114 (1996).

4. Nishimura, Y. et al. Determination of a statistically valid neutralization titer in plasma that confers protection against simian-human immunodeficiency virus challenge following passive transfer of high-titered neutralizing antibodies. J. Virol. 76, 2123-2130 (2002).

5. Letvin, N. L. et al. Vaccine-elicited V3 loop-specific antibodies in rhesus monkeys and control of a simian-human immunodeficiency virus expressing a primary patient human immunodeficiency virus type 1 isolate envelope. J. Virol. $\mathbf{7 5}$, 4165-4175 (2001)

6. Emini, E. A. et al. Prevention of HIV-1 infection in chimpanzees by gp120 V3 domain-specific monoclonal antibody. Nature 355, 728-730 (1992).

7. Gauduin, M. C., Safrit, J. T., Weir, R., Fung, M. S. \& Koup, R. A. Pre- and postexposure protection against human immunodeficiency virus type 1 infection mediated by a monoclonal antibody. J. Infect. Dis. 171, 1203-1209 (1995).

8. Shibata, $R$ et al. Neutralizing antibody directed against the HIV-1 envelope glycoprotein can completely block HIV-1/SIV chimeric virus infections of macaque monkeys. Nature Med. 5, 204-210 (1999).

9. Mascola, J. R. et al. Protection of macaques against vaginal transmission of a pathogenic HIV-1/SIV chimeric virus by passive infusion of neutralizing antibodies. Nature Med. $\mathbf{6}$ 207-210 (2000).

10. Scarlatti, G. et al. Mother-to-child transmission of human immunodeficiency virus type 1: correlation with neutralizing antibodies against primary isolates. J. Infect. Dis. $\mathbf{1 6 8}$, 207-210 (1993)

11. Pitt, J. et al. Human immunodeficiency virus (HIV) type 1 antibodies in perinatal HIV-1 infection: association with human HIV-1 transmission, infection, and disease progression. J. Infect. Dis. 182, 1243-1246 (2000).

12. Dimmock, N. J. Neutralization of animal viruses. Curr. Top. Microbiol. Immunol. 183, 1-149 (1993).

13. Burton, D. R. Antibodies, viruses and vaccines. Nature Rev. Immunol. 2, 706-713 (2002)

14. Hansen, J. E. et al. Inhibition of human immunodeficiency virus (HIV) infection in vitro by anticarbohydrate monoclonal antibodies: peripheral glycosylation of HIV envelope glycoprotein gp120 may be a target for virus neutralization. J. Virol. 64, 2833-2840 (1990).

15. Scanlan, C. N. et al. The broadly neutralizing anti-human immunodeficiency virus type 1 antibody $2 \mathrm{G} 12$ recognizes a cluster of $\alpha 1 \rightarrow 2$ mannose residues on the outer face of gp120. J. Virol. 76, 7306-7321 (2002).

16. Hioe, C. E., Bastiani, L., Hildreth, J. E. K. \& Zolla-Pazner, S. Role of cellular adhesion molecules in HIV type 1 infection and their impact on virus neutralization. AIDS Res. Hum. Retroviruses 14, 247-254 (1998).

17. Ugolini, S. et al. Inhibition of virus attachment to CD4+ target cells is a major mechanism of T cell line-adapted HIV-1 neutralization. J. Exp. Med. 186, 1287-1298 (1997).

18. Chan, D. C. \& Kim, P. S. HIV entry and its inhibition. Cell 93 681-684 (1998).

A review on aspects of the structural changes in HIV glycoprotein gp41 that occur as a consequence of conformational changes induced by interaction of gp120 with CD4 and chemokine receptors. The subsequent formation of the gp41 coiled-coil form leads to fusion between virus and cell membranes.

19. Gorny, M. K. \& Zolla-Pazner, S. Recognition of free and complexed peptides representing the prefusogenic and fusogenic forms of HIV-1 gp41 by human monoclonal antibodies. J. Virol. 74, 6186-6192 (2000).

20. Golding, H. et al. Dissection of human immunodeficiency virus type 1 entry with neutralizing antibodies to gp41 fusion intermediates. J. Virol. 76, 6780-6790 (2002).

21. Binley, J. M. et al. Redox-triggered infection by disulfide-shackled human immunodeficiency virus type 1 pseudovirions. J. Virol. 77, 5678-5684 (2003).

22. Spear, G. T., Takefman, D. M., Sharpe, S., Ghassemi, M. \& Zolla-Pazner, S. Antibodies to the HIV-1 V3 loop in serum from infected persons contribute a major proportion of immune effector functions including complement activation, antibody binding, and neutralization. Virology 204,609-615 (1994).

23. Tyler, D. S. et al. Identification of sites within gp 41 that serve as targets for antibody-dependent cellular cytotoxicity by using human monoclonal antibodies. J. Immunol. 145, 3276-3282 (1990).

24. Koup, R. A. et al. Antibody-dependent cell-mediated cytotoxicity directed by a human monoclonal antibody reactive with gp120 of HIV-1. AIDS 5, 1309-1314 (1991).

25. Check, E. AIDS vaccines: back to 'plan A'. Nature $\mathbf{4 2 4}$ 912-914 (2003).

26. Dowbenko, D. et al. Epitope mapping of the human immunodeficiency virus type $1 \mathrm{gp} 120$ with monoclonal antibodies. J. Virol. 62, 4703-4711 (1988).

27. Goudsmit, J. Immunodominant B-cell epitopes of the HIV-1 envelope recognized by infected and immunized hosts. AIDS 2 (Suppl. 1), S41-S45 (1988).
28. Broliden, P. A. et al. Identification of human neutralizationinducing regions of the human immunodeficiency virus type 1 envelope glycoproteins. Proc. Natl Acad. Sci. USA 89, 461-465 (1992).

29. Scala, G. et al. Selection of HIV-specific immunogenic epitopes by screening random peptide libraries with HIV-1-positive sera. J. Immunol. 162, 6155-6161 (1999).

30. Xu, J.-Y., Gorny, M. K., Palker, T., Karwowska, S. \& ZollaPazner, S. Epitope mapping of two immunodominant domains of gp41, the transmembrane protein of human immunodeficiency virus type 1 , using ten human monoclonal antibodies. J. Virol. 65, 4832-4838 (1991).

31. Binley, J. M. et al. Human antibody responses to HIV type 1 glycoprotein 41 cloned in phage display libraries suggest three major epitopes are recognized and give evidence for conserved antibody motifs in antigen binding. AIDS Res. Hum. Retroviruses 12, 911-924 (1996).

32. Trkola, A. et al. Cross-clade neutralization of primary isolates of human immunodeficiency virus type 1 by human monoclonal antibodies and tetrameric CD4-lgG. J. Virol. 69 6609-6617 (1995).

33. Parker, C. E. et al. Fine definition of the epitope on the gp41 glycoprotein of human immunodeficiency virus type 1 for the neutralizing monoclonal antibody, 2F5. J. Virol. 75 10906-10911 (2001).

34. Zwick, M. B. et al. Broadly neutralizing antibodies targeted to the membrane-proximal external region of human immunodeficiency virus type 1 glycoprotein gp 41 . J. Virol. 75 10892-10905 (2001)

35. Sattentau, Q. J., Zolla-Pazner, S. \& Poignard, P. Epitope exposure on functional, oligomeric HIV-1 gp41 molecules. Virology 206, 713-717 (1995).

36. Zolla-Pazner, S. et al. Serotyping of primary human immunodeficiency virus type 1 isolates from diverse geographic locations by flow cytometry. J. Virol. $\mathbf{6 9}$ 3807-3815 (1995).

37. Nyambi, P. N. et al. Conserved and exposed epitopes on intact, native, primary human immunodeficiency virus type 1 virions of group M. J. Virol. 74, 7096-7107 (2000)

38. He, Y. et al. Peptides trap the human immunodeficiency virus type 1 envelope glycoprotein fusion intermediate at two sites. J. Virol. 77, 1666-1671 (2003).

39. Zwick, M. B. et al. Identification and characterization of a peptide that specifically binds the human, broadly neutralizing anti-human immunodeficiency virus type 1 antibody b12. J. Virol. 75, 6692-6699 (2001).

40. Coeffier, E. et al. Antigenicity and immunogenicity of the HIV-1 gp41 epitope ELDKWA inserted into permissive sites of the MalE protein. Vaccine 19, 684-693 (2000).

41. Muster, T. et al. Cross-neutralizing antibodies against divergent human immunodeficiency virus type 1 isolates induced by the gp 41 sequence ELDKWAS. J. Virol. $\mathbf{6 8}$ 4031-4034 (1994). 
42. Eckhart, L. et al. Immunogenic presentation of a conserved gp41 epitope of human immunodeficiency virus type 1 on recombinant surface antigen of hepatitis B virus. J. Gen. Virol. 77, 2001-2008 (1996).

43. Cotropia, J. et al. A human monoclonal antibody to HIV-1 gp41 with neutralizing activity against diverse laboratory isolates. J. Acquir. Immune Defic. Syndr. Hum. Retrovirol. 12, 221-232 (1996).

44. Ferrantelli, F. et al. Potent cross-group neutralization of primary HIV isolates with monoclonal antibodies implications for AIDS vaccine. J. Infect. Dis. $\mathbf{1 8 9}$ 71-74 (2004).

45. Hioe, C. E. et al. Neutralization of HIV-1 primary isolates by polyclonal and monoclonal human antibodies. Int. Immunol. $\mathbf{9}$ 1281-1290 (1997).

46. Karwowska, S. et al. Production of human monoclonal antibodies specific for conformational and linear non-V3 epitopes of gp120. AIDS Res. Hum. Retroviruses 8 , 1099-1106 (1992).

47. Pinter, A., Honnen, W. J., Racho, M. E. \& Tilley, S. A A potent, neutralizing human monoclonal antibody against a unique epitope overlapping the CD4-binding site of HIVgp120 that is broadly conserved across North American and African virus isolates. AIDS Res. Hum. Retroviruses $\mathbf{9}$, 985-996 (1993)

48. D'Souza, M. P. et al. Neutralization of primary HIV-1 isolates by anti-envelope monoclonal antibodies. AIDS 9, 867-874 (1995).

49. Barbas, C. F. et al. Recombinant human Fab fragments neutralize human type 1 immunodeficiency virus in vitro. Proc. Natl Acad. Sci. USA 89, 9339-9343 (1992).

50. Kessler, J. A. et al. Recombinant human monoclonal antibody lgG1b12 neutralizes diverse human immunodeficiency virus type 1 primary isolates. AIDS Res. Hum. Retroviruses 13, 575-582 (1997).

51. Hioe, C. E. et al. Anti-CD4-binding domain antibodies complexed with HIV type 1 glycoprotein 120 inhibit CD4 T cell-proliferative responses to glycoprotein 120. AIDS Res. Hum. Retroviruses 16, 893-905 (2000).

52. Hioe, C. E. et al. Inhibition of human immunodeficiency virus type 1 gp120 presentation to CD4 T cells by antibodies specific for the CD4 binding domain of gp120. J. Virol. 75, 10950-10957 (2001)

53. Thali, M. et al. Characterization of conserved HIV-type 1 gp120 neutralization epitopes exposed upon gp120-CD4 binding. J. Virol. 67, 3978-3988 (1993).

54. Feng, Y., Broder, C. C., Kennedy, P. E. \& Berger, E. A. HIV-1 entry cofactor: functional cDNA cloning of a seventransmembrane, G protein-coupled receptor. Science $\mathbf{2 7 2}$ 872-877 (1996)

The first description of a molecule (later identified as CXC-chemokine receptor 4) as a co-receptor that is required for the infection of cells by T-cell-line-adapted strains of HIV-1.

55. Alkhatib, G., Berger, E. A., Murphy, P. M. \& Pease, J. E. Determination of HIV-1 coreceptor function on CC chemokine receptor 3 . Importance of both extracellular and transmembrane/cytoplasmic regions. J. Biol. Chem. 272, 20420-20426 (1997)

56. Deng, $\mathrm{H}$. et al. Identification of a major co-receptor for primary isolates of HIV-1. Nature 381, 661-666 (1996).

57. Xiang, S. H., Doka, N., Choudhary, R. K., Sodroski, J. \& Robinson, J. E. Characterization of CD4-induced epitopes on the HIV type 1 gp120 envelope glycoprotein recognized by neutralizing human monoclonal antibodies. AIDS Res. Hum. Retroviruses 18, 1207-1217 (2002).

58. Moulard, M. et al. Broadly cross-reactive HIV-1-neutralizing human monoclonal Fab selected for binding to gp120-CD4-CCR5 complexes. Proc. Natl Acad. Sci. USA 99, 6913-6918 (2002).

59. Kwong, P. D. et al. Structures of HIV-1 gp120 envelope glycoproteins from laboratory-adapted and primary isolates. Structure Fold Des. 8, 1329-1339 (2000).

60. Dey, B., Del Castillo, C. S. \& Berger, E. A. Neutralization of human immunodeficiency virus type 1 by sCD $4-17 \mathrm{~b}$, a single-chain chimeric protein, based on sequential interaction of gp120 with CD4 and coreceptor. J. Virol. 77 , 2859-2865 (2003)

61. Sullivan, N. et al. CD4-induced conformational changes in the human immunodeficiency virus type $1 \mathrm{gp} 120$ glycoprotein: consequences for virus entry and neutralization. J. Virol. 72, 4694-4703 (1998).

A description of the nature and functional significance of conformational changes in gp120 that are induced by soluble CD4.

62. Sodroski, J in Retroviruses of Human AIDS and Related Animal Diseases (eds Vicari, M., Dodet, B. \& Girard, M.) 25-27 (Elsevier, Paris, 2002).

63. Leonard, C. K. et al. Assignment of intrachain disulfide bonds and characterization of potential glycosylation sites of the type 1 recombinant human immunodeficiency virus envelope glycoprotein (gp120) expressed in Chinese hamster ovary cells. J. Biol. Chem. 265, 10373-10382 (1990).

64. Trkola, A. et al. Human monoclonal antibody $2 \mathrm{G} 12$ defines a distinctive neutralization epitope on the gp120 glycoprotein of human immunodeficiency virus type 1. J. Virol. 70, 1100-1108 (1996).

65. Calarese, D. A. et al. Antibody domain exchange is an immunological solution to carbohydrate cluster recognition. Science 300, 2065-2071 (2003).

66. Fung, M. S. et al. Identification and characterization of a neutralization site within the second variable region of HIV-type 1 gp120. J. Virol. 66, 848-856 (1992).

67. Gorny, M. K. et al. Human anti-V2 monoclonal antibody that neutralizes primary but not laboratory isolates of HIV-1. J. Virol. 68, 8312-8320 (1994)

68. Javaherian, K. et al. Principal neutralizing domain of the human immunodeficiency virus type 1 envelope protein Proc. Natl Acad. Sci. USA 86, 6768-6772 (1989).

69. Putney, S. D. et al. HTLV-III/LAV-neutralizing antibodies to an E. coli-produced fragment of the virus envelope. Science 234, 1392-1395 (1986).

70. Gorny, M. K. et al. Production of site-selected neutralizing human monoclonal antibodies against the third variable domain of the HIV-1 envelope glycoprotein. Proc. Nat Acad. Sci. USA 88, 3238-3242 (1991).

71. Robinson, H. L. New hope for an AIDS vaccine. Nature Rev. Immunol. 2, 239-250 (2002).

72. He, Y. et al. Efficient isolation of novel human monoclonal antibodies with neutralizing activity against HIV- 1 from transgenic mice expressing human Ig loci. J. Immunol. 169, 595-605 (2002)

73. Pinter, A., Honnen, W. J., Kayman, S. C., Trochev, O. \& $\mathrm{Wu}, \mathrm{Z}$. Potent neutralization of primary HIV-1 isolates by antibodies directed against epitopes present in the V1 N2 domain of HIV-1 gp120. Vaccine 16, 1803-1811 (1998)

74. Cao, J. et al. Replication and neutralization of human immunodeficiency virus type 1 lacking the $\mathrm{V} 1$ and $\mathrm{V} 2$ variable loops of the gp120 envelope glycoprotein. J. Virol. 71, 9808-9812 (1997).

75. Stamatatos, L. \& Cheng-Mayer, C. An envelope modification that renders a primary, neutralization-resistant clade B human immunodeficiency virus type 1 isolate highly susceptible to neutralization by sera from other clades. J. Virol. 72 7840-7845 (1998)

76. Center, R. J., Earl, P. L., Lebowitz, J., Schuck, P. \& Moss, B. The human immunodeficiency virus type $1 \mathrm{gp} 120 \mathrm{~V} 2$ domain mediates gp41-independent intersubunit contacts. J. Virol. 74, 4448-4455 (2000).

77. Rizzuto, C. D. et al. A conserved HIV gp120 glycoprotein structure involved in chemokine receptor binding. Science 280, 1949-1953 (1998).

78. Wyatt, R. et al. Involvement of the V1/N2 variable loop structure in the exposure of human immunodeficiency virus type $1 \mathrm{gp} 120$ epitopes induced by receptor binding J. Virol. 69, 5723-5733 (1995)

79. Wyatt, R. et al. Functional and immunologic characterization of human immunodeficiency virus type 1 envelope glycoproteins containing deletions of the major variable regions. J. Virol. 67, 4557-4565 (1993).

80. Srivastava, I. K., VanDorsten, K., Vojtech, L., Barnett, S. W. \& Stamatatos, L. Changes in the immunogenic properties of soluble gp140 human immunodeficiency virus envelope constructs upon partial deletion of the second hypervariable region. J. Virol. 77, 2310-2320 (2003).

81. Kwong, P. D. et al. Structure of an HIV gp120 envelope glycoprotein in complex with the CD4 receptor and a neutralizing human antibody. Nature $\mathbf{3 9 3}, 648-659$ (1998).

Presentation of the crystal structure of a truncated core form of gp120 from a T-cell-line-adapted virus.

82. Goudsmit, J. et al. Human immunodeficiency virus type 1 neutralization epitope with conserved architecture elicits early type-specific antibodies in experimentally infected chimpanzees. Proc. Natl Acad. Sci. USA 85, 4478-4482 (1988).

83. Mascola, J. R et al. Immunization with envelope subunit vaccine products elicits neutralizing antibodies against laboratory-adapted but not primary isolates of human immunodeficiency virus type 1. J. Infect. Dis. 173, 340-348 (1996).

84. Gorny, M. K. et al. Human monoclonal antibodies to the V3 loop of HIV-1 with intra- and interclade cross-reactivity. J. Immunol. 159, 5114-5122 (1997).

85. Gorny, M. K., Xu, J.-Y., Karwowska, S., Buchbinder, A. \& Zolla-Pazner, S. Repertoire of neutralizing human monoclonal antibodies specific for the V3 domain of HIV-1 gp120. J. Immunol. 150, 635-643 (1993).

86. Gorny, M. K. et al. Human monoclonal antibodies specific for conformation-sensitive epitopes of V3 neutralize HIV-1 primary isolates from various clades. J. Virol. 76 9035-9045 (2002)

87. Conley, A. J. et al. Neutralization of primary human immunodeficiency virus type 1 isolates by the broadly reactive anti-V3 monoclonal antibody, 447-52D. J. Virol. 68 6994-7000 (1994).

88. Krachmarov, C. P., Kayman, S. C., Honnen, W. J., Trochev, O. \& Pinter, A. V3-specific polyclonal antibodies affinity purified from sera of infected humans effectively neutralize primary isolates of human immunodeficiency virus type 1. AIDS Res. Hum. Retroviruses 17, 1737-1748 (2001)

89. Gorny, M. K. et al. The V3 loop is accessible on the surface of most HIV-1 primary isolates and serves as a neutralization epitope. J. Virol. (in the press).

90. Poignard, P. et al. Heterogeneity of envelope molecules expressed on primary human immunodeficiency virus type particles as probed by the binding of neutralizing and nonneutralizing antibodies. J. Virol. 77, 353-365 (2003).

91. Andris, J. S., Johnson, S., Zolla-Pazner, S. \& Capra, J. D. Molecular characterization of five human anti-HIV-1 antibody heavy chains reveals extensive somatic mutation typical of an antigen-driven immune response. Proc. Natl Acad. Sci. USA 88, 7783-7787 (1991).

92. Kwong, P. D., Wyatt, R., Sattentau, Q. J., Sodroski, J. \& Hendrickson, W. A. Oligomeric modeling and electrostatic analysis of the gp120 envelope glycoprotein of human immunodeficiency virus. J. Virol. 74, 1961-1972 (2000).

93. Cormier, E. G. \& Dragic, T. The crown and stem of the V3 loop play distinct roles in human immunodeficiency virus type 1 envelope glycoprotein interactions with the CCR5 coreceptor. J. Virol. 76, 8953-8957 (2002).

94. Suphaphiphat, P., Thitithanyanont, A., Paca-Uccaralertkun, S. Essex, M. \& Lee, T. H. Effect of amino acid substitution of the $\mathrm{V} 3$ and bridging sheet residues in human immunodeficiency virus type 1 subtype $\mathrm{C}$ gp120 on CCR5 utilization. J. Virol. 77, 3832-3837 (2003).

95. Sharon, M. et al. Alternative conformations of HIV-1 V3 loops mimic $\beta$ hairpins in chemokines, suggesting a mechanism for coreceptor selectivity. Structure $\mathbf{1 1}$ 225-236 (2003).

This paper describes structural homology between the V3 loop of gp120 and $\beta$-hairpin structures in CC- and CXC-chemokines, providing an explanation for how the envelope proteins of R5 and X4 viruses selectively use the receptors for these chemokines to gain entry into cells.

96. Yonezawa, A., Hori, T., Takaori-Kondo, A., Morita, R. \& Uchiyama, T. Replacement of the $\mathrm{V} 3$ region of gp120 with SDF-1 preserves the infectivity of $\mathrm{T}$-cell line-tropic human immunodeficiency virus type 1. J. Virol. 75, 4258-4267 (2001).

97. VanCott, T. C. et al. Differential role of V3-specific antibodies in neutralization assays involving primary and laboratoryadapted isolates of HIV type 1. AIDS Res. Hum. Retroviruses 11, 1379-1391 (1995).

98. Spenlehauer, C. et al. Study of the V3 loop as a target epitope for antibodies involved in the neutralization of primary isolates versus T-cell-line-adapted strains of human immunodeficiency virus type 1. J. Virol. 72, 9855-9864 (1998).

99. Bou-Habib, D. C. et al. Cryptic nature of envelope V3 region epitopes protects primary monocytotropic human immunodeficiency virus type 1 from antibody neutralization. J. Virol. 68, 6006-6013 (1994).

100. Cavacini, L. \& Posner, M. Native HIV-1 virion surface structures: relationships between antibody binding and neutralization or lessons from the viral capture assay. AIDS Res. Hum. Retroviruses (in the press)

101. Stamatatos, L., Zolla-Pazner, S., Gorny, M. K. \& ChengMayer, C. Binding of antibodies to virion-associated gp120 molecules of primary-like human immunodeficiency virus type 1 (HIV-1) isolates: effect on HIV-1 infection of macrophages and peripheral blood mononuclear cells. Virology 229, 360-369 (1997).

102. Bhattacharyya, D., Brooks, B. R. \& Callahan, L. Positioning of positively charged residues in the V3 loop correlates with HIV type 1 syncytium-inducing phenotype. AIDS Res. Hum Retroviruses 12, 83-90 (1996).

103. Laurence, J. S., Blanpain, C., De Leener, A., Parmentier, M. \& LiWang, P. J. Importance of basic residues and quaternary structure in the function of MIP-1 $\beta$ : CCR5 binding and cell surface sugar interactions. Biochemistry 40, 4990-4999 (2001).

104. Palker, T. J. et al. A conserved region at the $\mathrm{COOH}$ terminus of human immunodeficiency virus gp120 envelope protein contains an immunodominant epitope. Proc. Natl Acad. SCl. USA 84, 2479-2483 (1987).

105. Barnett, S. W. et al. The ability of an oligomeric human immunodeficiency virus type 1 (HIV-1) envelope antigen to elicit neutralizing antibodies against primary HIV-1 isolates is improved following partial deletion of the second hypervariable region. J. Virol. 75, 5526-5540 (2001). 
106. Pantophlet, R., Wilson, I. A. \& Burton, D. R. Hyperglycosylated mutants of human immunodeficiency virus (HIV) type 1 monomeric gp120 as novel antigens fo HIV vaccine design. J. Virol. 77, 5889-5901 (2003).

107. Kelker, H. C., Schlesinger, D. \& Valentine, F. T. Immunogenic and antigenic properties of an HIV-1 gp120-derived multiple chain peptide. J. Immunol. 152, 4139-4148 (1994).

108. Liao, H. X. et al. Induction of antibodies in guinea pigs and rhesus monkeys against the human immunodeficiency virus type 1 envelope: neutralization of nonpathogenic and pathogenic primary isolate simian/human immunodeficiency virus strains. J. Virol. 74, 254-263 (2000).

109. Berger, C. L., Longley, J., Hanlon, D., Girardi, M. \& Edelson, R. The clonotypic T cell receptor is a source of tumor-associated antigens in cutaneous T cell lymphoma. Ann. NY Acad. Sci. 941, 106-122 (2001).

110. Keller, P. M. et al. Identification of HIV vaccine candidate peptides by screening random phage epitope libraries. Virology 193, 709-716 (1993)

111. Saphire, E. O. et al. Crystal structure of a neutralizing human IgG against HIV-1: a template for vaccine design. Science 293, 1155-1159 (2001).

112. Saphire, E. O. et al. Contrasting lgG structures reveal extreme asymmetry and flexibility. J. Mol. Biol. 319, 9-18 (2002).

113. Tugarinov, V. et al. NMR structure of an anti-gp120 antibody complex with a $\mathrm{V} 3$ peptide reveals a surface important for co-receptor binding. Structure Fold Des. 8, 385-395 (2000).

114. Frangione-Beebe, M. et al. Enhanced immunogenicity of a conformational epitope of human T-lymphotropic virus type using a novel chimeric peptide. Vaccine 19, 1068-1081 (2000).

115. Steward, M. W., Stanley, C. M. \& Obeid, O. E. A mimotope from a solid-phase peptide library induces a measles virusneutralizing and protective antibody response. J. Virol. 69, 7668-7673 (1995).

116. Yu, M. W., Scott, J. K., Fournier, A. \& Talbot, P. J. Characterization of murine coronavirus neutralization epitopes with phage-displayed peptides. Virology $\mathbf{2 7 1}$ 182-196 (2000).
117. Grabowska, A. M. et al. Immunisation with phage displaying peptides representing single epitopes of the glycoprotein $\mathrm{G}$ can give rise to partial protective immunity to HSV-2. Virology 269, 47-53 (2000).

118. Weber, J. et al. Neutralization serotypes of HIV-1 field isolates are not predicted by genetic subtype. J. Virol. 70 7827-7832 (1996).

119. Nyambi, P. N. et al. Multivariate analysis of human immunodeficiency virus type 1 neutralization data. J. Virol. 70, 6235-6243 (1996).

120. Moore, J. P. et al. Inter- and intraclade neutralization of human immunodeficiency virus type 1: genetic clades do not correspond to neutralization serotypes but partially correspond to gp120 antigenic serotypes. J. Virol. 70 427-444 (1996).

121. Mascola, J. R. et al. Human immunodeficiency virus type 1 neutralizing antibody serotyping using serum pools and an infectivity reduction assay. AIDS Res. Hum. Retroviruses $\mathbf{1 2}$ 1319-1328 (1996).

122. Moore, J. P. et al. A human monoclonal antibody to a complex epitope in the $\mathrm{V} 3$ region of gp120 of human immunodeficiency virus type 1 has broad reactivity within and outside clade B. J. Virol. 69, 122-130 (1995).

23. De Groot, A. S. et al. Designing HIV-1 vaccines to reflect vira diversity and the global context of HIV/AIDS. AIDScience $\mathbf{1}$, 1-24 (2001).

124. Gaschen, B. et al. Diversity considerations in HIV-1 vaccine selection. Science 296, 2354-2360 (2002)

125. Zolla-Pazner, S., Gorny, M. K., Nyambi, P. N., VanCott, T. C. \& Nadas, A. Immunotyping of human immunodeficiency virus type 1 (HIV): an approach to immunologic classification of HIV. J. Virol. 73, 4042-4051 (1999).

126. Gallaher, W. R., Ball, J. M., Garry, R. F., Griffin, M. C. \& Montelaro, R. C. A general model for the transmembrane proteins of HIV and other retroviruses. AIDS Res. Hum. Retroviruses 5, 431-440 (1989).

127. Cohen, J. HIV. Escape artist par excellence. Science $\mathbf{2 9 9}$ 1505-1508 (2003).

128. Muster, T. et al. A conserved neutralizing epitope on gp41 of human immunodeficiency virus type 1. J. Virol. 67, 6642-6647 (1993).
129. Ho, D. D. et al. Conformational epitope on gp120 important in CD4 binding and human immunodeficiency virus type 1 neutralization identified by a human monoclonal antibody. J. Virol. 65, 489-493 (1991).

130. Gorny, M. K. et al. Neutralization of diverse HIV-1 variants by an anti-V3 human monoclonal antibody. J. Virol. 66 , 7538-7542 (1992)

131. Scott, C. F. et al. Human monoclonal antibody that recognizes the $\mathrm{V} 3$ region of $\mathrm{HIV}$ gp120 and neutralizes the human T-lymphotropic virus type III-MN strain. Proc. Natl Acad. Sci. USA 87, 8597-8601 (1990).

132. Labrijn, A. F. et al. Access of antibody molecules to the conserved coreceptor binding site on glycoprotein gp120 is sterically restricted on primary human immunodeficiency virus type 1. J. Virol. 77, 10557-10565 (2003).

133. Stanfield, R. L. et al. Structural rational for the broad neutralisation of $\mathrm{HIV}-1$ by human monoclonal antibody 447-52D. Structure 12, 1-20 (2004).

Acknowledgements

Supported in part by the Research Enhancement Award Program and research grants from the Department of Veterans Affairs and the National Institutes of Health. Assistance with preparation of the figures by M. Shapira and F. Camacho is gratefully acknowledged.

Competing interests statement

The author declares that she has no competing financial interests.

\section{(2) Online links}

\section{DATABASES}

The following terms in this article are linked online to:

LocusLink: http://www.ncbi.nlm.nih.gov/LocusLink CCL3 | CCL4 | CCL5 | CCR5 | CD4 | CXCL12 | CXCR4

FURTHER INFORMATION

Los Alamos National Labs HIV sequence database:

http://www.hiv.lanl.gov/content/index

UNAIDS web site: http://www.unaids.org/en/default.asp

Access to this interactive links box is free online. 